\title{
СТРУКТУРНО-СОДЕРЖАТЕЛЬНЫЙ АСПЕКТ МЕТОДОЛОГИЧЕСКОГО КОМПОНЕНТА СОДЕРЖАНИЯ ОБУЧЕНИЯ ИНОСТРАННОМУ ЯЗЫКУ В УСЛОВИЯХ ЦИФРОВИЗАЦИИ ОБРАЗОВАНИЯ
}

Статья посвящена рассмотрению структурно-содержательного аспекта методологического компонента содержания обучения иностранному языку в эпоху чифровизации образования. В период мировой интеграции, информатизации и компьютеризации всех сфер человеческой жсизни формируется единое культурное пространство, в результате чего изменению подвержена и система образования как сочиокультурный феномен. Обучение иностранному языку становится необходимым условием для нормального сосуцествования индивидов различных этносов. $B$ данном прочессе методологический компонент содержания обучения является важным инструментом для овладения иностранным языком. Подобная постановка проблемы включает такие аспекты, как место и роль методологического компонента в структурной основе содержания обучения с дальнейшим определением его сущности. В связи с этим в статье осуществляется исследование таких аспектов проблемы, как состояние современной системы образования и прочесс ее цифровизачии в контексте информатизации общества. В результате анализа делается вывод о том, что в данных условиях роль и место методологического компонента определяются характером современного обиества и тенденцией к иифровизации, а в контексте статьи - на уровне методов и приемов овладения иностранным языком в коммуникативном предъявлении.

Ключевые слова: содержание обучения, методологический компонент, система образования, циирровизация образования, мобильное обучение.

\section{Telman Grigoryan, Tatiana Lomteva STRUCTURAL-CONTENT ASPECT OF THE METHODOLOGICAL COMPONENT OF THE CONTENT OF TEACHING A FOREIGN LANGUAGE IN THE CONDITIONS OF DIGITALIZATION OF EDUCATION}

The article is devoted to the consideration of the content of teaching a foreign language in the era of digitalization of education. During the period of world integration, informatization and computerization of all spheres of human life, a common cultural space is formed, as a result of which the education system is also subject to change as a sociocultural phenomenon. Learning a foreign language becomes a necessary condition for the normal coexistence of individuals of different ethnic groups. In this process, the methodological component of the content of teaching is an important tool for mastering a foreign language. Similar statement of the problem includes such aspects as the place and the role of the methodological component in a structural basis of content of teaching with further determination of its essence. In this regard, the article studies such aspects of the problem as the state of the modern education system and the process of its digitalization in the context of the informatization of society. The analysis concludes that in these conditions the role and place of the methodological component is determined by the nature of modern society and the tendency towards digitalization in the context of the article - at the level of methods and techniques for mastering a foreign language in communicative presentation.

Key words: content of teaching, methodological component, education system, digitalization of education, mobile training.

Bведение / Introduction. В XXI веке, когда происходит всеобщая интеграция в мировой экономике и стремительно развиваются современные информационные технологии параллельно с компьютеризацией всех сфер жизнедеятельности человека, формируется так называемое единое мировое культурное пространство. Данные социокультурные реалии ставят перед обществом 
новые задачи, которые направлены на решение вопросов, связанных с обеспечением стабильного социума и достижением социального равноправия, что возможно на базе новейших ценностей, новых отношений между различными этносами, что невозможно без преодоления как культурных, так и языковых (лингвистических) барьеров. Все эти факторы, безусловно, в большой мере влияют и на процесс обучения иностранному языку. В свою очередь, содержание обучения иностранному языку является составной частью данного процесса. В этих условиях качественным изменениям подвергаются все компоненты содержания обучения иностранному языку, к которым традиционно относят лингвистический, методологический, социолингвистический, социокультурный и психологический (Н. Д. Гальскова, Н. А. Камнева, Г. В. Рогова).

В этой иерархии компонентов методологический занимает особое место, так как усвоить знание возможно только благодаря деятельности, то есть с помощью рациональных приемов и методов учения учащийся сможет овладеть иностранным языком.

Maтериалы и методы / Materials and methods. Методологический компонент содержания обучения подразумевает овладение учащимися наиболее рациональными приемами обучения, умение пользоваться учебниками, грамматическим справочником, словарем, звуко- и видеозаписью, различными информационными технологиями, способствующими познанию нового для них иностранного языка. Немаловажны и навыки организации самостоятельной работы, самоконтроля, самоанализа, планирования учебной деятельности [5]. Методологический компонент подвержен изменениям, связанным с эволюцией системы образования.

Под системой образования принято понимать «совокупность преемственных образовательных программ и государственных образовательных стандартов различного уровня и направленности; сети реализующих их образовательных учреждений различных организационно-правовых форм, типов и видов; системы органов управления образованием и подведомственных им учреждений и предприятий [7, с. 150].

В современных условиях это открытая, непрерывно развивающаяся система, для которой характерен ряд тенденций.

Гуманизация - ориентация системы образования на создание и устойчивое становление уважительных взаимоотношений между учащимися и педагогами, основанных на взаимном признании прав и свобод человека, сохранении и укреплении здоровья, чувства собственного достоинства, формировании личностного потенциала.

Гуманитаризация - направленность на постижение содержания образования любого уровня и типа; беспрепятственное общение лиц различных национальностей и конфессий; хорошее знание родного языка и свободное владение иностранным; необходимое познание в области национального и мирового культурного наследия; уровень экономической и юридической грамотности человека.

Дифференциация образования, которая может воплощаться на практике разными способами, например, через группировку обучаемых по признаку успеваемости, разделение учебных дисциплин на обязательные и по выбору, разделение учебных заведений на элитарные, массовые и предназначенные для обучаемых с задержками или отклонениями в развитии, составление индивидуальных планов для отдельных учащихся или студентов в соответствии с их интересами и профессиональной ориентацией и др.

Диверсификация - большое количество разнообразных учебных заведений, программ в сфере образования и органов контроля.

Стандартизация - в центре образовательной системы находится государственный образовательный стандарт (набор обязательных учебных дисциплин в четко определенном объеме часов), который является основной целью для реализации.

Многовариантность - каждый субъект образовательной системы имеет выбор и шанс на успех. 
Многоуровневость - образовательный процесс состоит из многочисленных этапов, которые обеспечивают возможность для учащегося достичь на каждом этапе своего уровня, соответствующего интересам и способностям человека. Уровни являются периодами, которым соответствуют определенные цели и задачи, а также сроки обучения и отличительные характеристики.

Информатизация - проникновение во все сферы человеческой жизни как вычислительных технологий, так и техники информационного характера.

Индивидуализсция - учитываются индивидуальные характеристики учащихся и студентов как в форме взаимодействия, так и в процессе обучения и воспитания.

Непрерывность - человек самосовершенствуется и постоянно получает новое образование, тем самым подстраиваясь под быстро меняющиеся жизненные условия современного социума [4].

Одной из самых актуальных и важных тенденцией образования является именно информатизация. Информация является базисом современной эпохи постмодерна, более того, она является объектом обмена при взаимодействии различных информационных процессов. Информационное пространство с помощью глобальной сети позволяет расширить все имеющиеся социальные возможности, которые являются ключом к преодолению политических и географических границ, что, в свою очередь, является условием для доступа каждого к мировым ценностям, «виртуализируя〉 сферу экономической деятельности человека. Все это есть предлог быстрой информатизации общества, что приводит к всеобщей цифровизации социальных явлений и условий.

Термин «информатизация» становится все менее актуальным, поколение, родившееся и подрастающее уже в ходе процесса, живет в цифровом формате. Формат традиционной культуры со сложившейся системой ценностей это поколение воспринимает сквозь призму цифры и появляющихся следствий: таких как клип-культура, экранная культура, культура компьютерных игр и т. п. [2].

Цифровизация как социальное явление получила распространение в 60-70-е годы XX века, ее характеризуют три ведущих характеристики:

1) все виды контента переходят из аналоговых, физических и статичных в цифровые, одновременно становятся мобильными и персональными. При этом индивид получает возможность контролировать свой личный контент, направлять информационные запросы, формировать индивидуальную траекторию информационной деятельности;

2) осуществляется переход к простым технологиям коммуникации (технология становится лишь средством, инструментом общения), ведущая характеристика устройства и технологии - управляемость.

3) коммуникации становятся гетерогенными: вертикальная, иерархичная коммуникация теряет актуальность, происходит переход к сетевой структуре коммуникации [6].

В современном мире система образования также прошла все уровни информатизации и компьютеризации. Эти этапы были зависимы как от финансового состояния всех элементов образовательной системы, так и от степени развития университетов и от степени готовности преподавателей и профессоров.

Процесс цифровизации является социальным независимым феноменом, который внедряется во все сферы человеческой жизни без дополнительных ресурсов. Основными характеристиками цифровизации являются удобное и простое использование изображения и возможность быстрой передачи данных. Для культурного пространства ценность цифровых технологий является достаточно значимой вне зависимости от их и положительного, и отрицательного воздействия. «С их распространением происходят изменения, которые затрагивают повседневную жизнь людей, устоявшиеся культурные иерархии, способы, которыми люди взаимодействуют друг с другом и миром вокруг них. Меняется система формирования культурного опыта в целом, все базовые сферы культуры» [10, с. 6]. 
Учитывая вышесказанное, можно сделать вывод: попадание в цифровую среду является неотьемлемой частью современного социума. Данный процесс происходит неосознанно задолго до выбора и понимания человеком своих личностных интересов и возможностей.

Явно, что именно сейчас необходимо создавать специальную программу цифровой трансформации для перехода к новой конкурентоспособной модели образования и научно-исследовательской среды. Все университеты, независимо от стратегического направления развития, должны пройти данное цифровое обновление. Переход к цифровому университету подразумевает внедрение оптимизированных и бесшовных процессов, смену культуры корпоративного взаимодействия.

Данные современные условия наталкивают на скорейший переход к цифровизации, так как нынешнее поколение студентов является цифровым поколением («digital natives»), они показывают высокий уровень владения цифровыми технологиями в своей ежедневной жизни. К этим цифровым технологиям относятся ИТ и интернет-технологии, а также их использование как в профессиональной деятельности, так и в сфере социальной коммуникации. Иными словами, цифровая трансформация университета позволит ему стать наиболее подходящим для современного поколения студентов.

Таким образом, говоря о методологическом компоненте содержания обучения иностранному языку, мы не можем не учитывать данной потребности общества, связанной с цифровизацией социума. Это проявляется в применении цифровых приемов и методов в процессе обучения иностранному языку. Дидактическая сущность применения данных средств обучения состоит в том, что создаются мультисенсорные комплексы учебной техники и автоматизированных обучающих систем, которые способствуют ведению учебной деятельности в диалоговом режиме, учитывая индивидуальные особенности каждого обучающегося.

Один из значимых методов обучения в условиях цифровизации - мобильное обучение. Термин «мобильное обучение», или m-learning, является уже неотъемлемой частью нашей жизни. Так как социальный прогресс сопровождается изменением стиля и качества нашей жизни, то и методы, и приемы обучения параллельно подвержены этим изменениям.

Большое количество исследователей, которые занимаются проблемой применения ИТ и интернет-технологий для обучения, отмечают, что процесс информатизации и цифровизации общества позволяет разработать и создать специальные мобильные коммуникативно направленные программы и приложения для повышения возможности и качества образования. Поколение студентов «digital natives» как никто другой демонстрирует современные реалии. Мобильные телефоны и другие устройства привели к тому, что нынешняя молодежь привыкла получать информацию и ее обрабатывать небольшими частями, а самое важное - заниматься этим в любом месте и в любое время (в метро, автобусе, во время ожидания очереди, т. е. совмещая с основной деятельностью) [3].

Мобильное обучение является частью электронного и дистанционного образования, так как с помощью портативных устройств возможно проводить такие виды образования в любых местах времяпровождения. То есть мобильное обучение позволяет получать знания без ограничения [9].

Учеными Н. В. Бабичевым, Е. Н. Водостоевым, О. Н. Масленниковым, а также Н. Ю. Соколовым были определены дидактические функции мобильного обучения:

1) познавательная - служащая для интеллектуальных и профессиональных целей;

2) диагностическая - определяющая способности обучающихся и начальный уровень знаний;

3) адаптационная - формирующая информационную культуру, навыки профессионального менеджмента;

4) пропедевтическая - осуществляющая педагогическую поддержку в процессе обучения; 
5) ориентационная - формирующая у обучающихся внутреннюю осознанность и готовность к самостоятельной расстановке перспектив;

6) функция управления учебной деятельностью - позволяющая вести учет познавательных возможностей обучающихся;

7) контроля - отслеживающая корректность выполнения итоговых работ;

8) прогностическая - осуществляющая прогноз возможностей обучаемого в процессе освоения нового материала [1].

Если говорить о мобильных средствах, которые можно было бы применять в процессе обучения иностранному языку для более высокой его эффективности, то к ним будут относиться мобильные телефоны, планшеты, ноутбуки и нетбуки. Эти цифровые средства позволяют передавать данные с помощью GPRS- или WAP-технологий. Основными достоинствами цифровых технологий, которые позволяют проводить мобильное обучение, являются портативность и постоянная возможность работы с Интернет-сетью.

Голосовая связь, обмен информацией, обмен изображениями, выход в Интернет являются основными функциями этих мобильных технологий. И это не весь список функций, которые повышают эффективность обучения иностранному языку.

Один из видов заданий, в котором применяются данные цифровые технологии, - веб-квест (Web Quest). Веб-квест - вид учебной деятельности проблемного характера с элементами ролевой игры. Основной особенностью этого вида заданий является выход в Интернет с дальнейшим использованием информационных ресурсов и источников. Веб-квест направлен на развитие поисковых навыков студентов и учащихся в Интернете. В результате данной деятельности должен быть разработан исследовательский проект. Веб-квест составляется как преподавателем, так и учащимся, в зависимости от целей учебного процесса [6].

Основным преимуществом рода такой деятельности является то, что в процессе поиска можно натолкнуться на различные по содержанию информации сайты в сети Интернет, которые введут учащегося в заблуждение, но у студента уже будет иметься список нужных и подходящих сайтов, соответствующих теме и уровню сложности заданной задачи. Благодаря тому что список сайтов заблаговременно подготавливается педагогом-преподавателем студент может правильно ориентироваться во времени, тем самым делать акцент не на поиск информации, а на ее использование.

Результаты и обсуждение / Results and discussion. Итак, к дидактическим свойствам мобильных технологий следует отнести высокую скорость обмена данными, диалоговый характер коммуникации, обеспечивающий интерактивный режим работы, гипертекст и мультимедиа, облегченный интерфейс сложноструктурированной информации.

В обшем, необходимо отметить, что цифровые технологии выводят обучение иностранному языку на новый уровень. Это сопровождается тем, что они не только ускоряют процесс обучения иностранному языку, но и делают его более легким и эффективным. Появляется необходимость в правильном и постепенном внедрении их как в образование в целом, так и конкретно в процесс обучения иностранному языку, ведь процесс цифровизации диктуется состоянием современного общества. Поэтому соответствие учебного процесса обучения иностранному языку условиям эпохи информационных технологий становится необходимым фактором для эффективного и правильного овладения иностранным языком.

Методологический компонент содержания обучения в этих условиях больше всех подвержен изменениям, так как появляются новые методы и приемы обучения, которые входят в его структуру. То есть данный компонент становится более актуальным, чем другие структурно-содержательные элементы содержания обучения в целом.

Заключение / Conclusion. Таким образом, можно сделать вывод о том, что роль методологического компонента остается неизменно важной, а его место определяется характером современного общества и тенденцией к цифровизации. Также необходимо отметить, что данный 
компонент способен ответить на важные вызовы современного этапа развития образовательных систем, поддерживая такие качества данного социокультурного феномена, как гуманизация, гуманитаризация, дифференциация, стандартизация, многовариантность, многоуровневость, информатизация, индивидуализация, непрерывность.

\section{ЛИТЕРАТУРА И ИНТЕРНЕТ-РЕСУРСЫ}

1. Бабичев Н. В. Роль и значение интерактивных наглядных пособий в системе современного биологического образования / Н. В. Бабичев, Е. Н. Водостоева, О. Н. Масленикова, Н. Ю. Соколова // Информатика и образование. 2008. № 9. URL: http://e-drofa.ru/aboutnavigator (дата обращения: 18.05.2017).

2. Галкин Д. В. От кибернетических автоматов к искусственной жизни: теоретические и историко-культурные аспекты формирования цифровой культуры: автореф. дис. ... д-ра философ. наук. Томск, 2013. $-51 \mathrm{c}$.

3. Злобина С. Н., Глушач Н. Н. Креативно-ориентированное образование - новый образовательный путь подготовки современных специалистов // Междунар. науч. школа психологии и педагогики VII (15). Новосибирск, 2015. С. 33-36.

4. Кавецкий И. Т. Основы психологии и педагогики / И. Т. Кавецкий, Т. Л. Рыжковская, И. А. Коверзнева, В. Г. Игнатович, Н. А. Лобан, С. В. Старовойтова. Минск: Изд-во МИУ, 2010

5. Камнева Н. А. Содержание обучения профессионально-ориентированному иностранному языку // Конференция: Гуманитарное образование в экономическом вузе - 2016. URL: http://sdo.rea.ru/cde / conference/23/file.php?fileId $=62 \mathrm{k}$

6. Николаева Н. В. Образовательные квест-проекты как метод и средство развития навыков информационной деятельности учащихся // Вопросы Интернет-образования. 2002. № 7. URL: http://vio.fio.ru/ vio_07 (дата обращения: 15.03.2017)

7. Полонский В. М. Научно-педагогическая информация: словарь-справочник. М.: Новая школа, 1995. $-256 \mathrm{c}$.

8. Сергеева И. Л. Трансформация массовой культуры в цифровой среде // Культура и цивилизация. 2016. T. 6. № 6A. C. 55-65.

9. Сигов А. С., Мордвинов В. А., Трифонов Н. И. Моделирование использования карманных компьютеров в дистанционном образовании // Информационные технологии в образовании: сб. науч. тр. М.: МИФИ, 2000. Ч. III. С. $79-80$

10. Соколова Н. Л. Цифровая культура или культура в цифровую эпоху [Электронный ресурс] // Международный журнал исследований культуры. 2012. № 3. C. 6-10. URL: http://www.culturalresearch.ru/ files/open_issues/03_2012/IJCR_03\%288\%29_2012.pdf.

\section{REFERENCES AND INTERNET RESOURCES}

1. Babichev N. V. Rol' i znachenie interaktivny'x naglyadny'x posobij $v$ sisteme sovremennogo biologicheskogo obrazovaniya (The role and importance of interactive visual aids in the system of modern biological education) / N. V. Babichev, E. N. Vodostoeva, O. N. Maslenikova, N. Yu. Sokolova// Informatika i obrazovanie. 2008. № 9. URL: http://e-drofa.ru/aboutnavigator (data obra- shheniya: 18.05.2017).

2. Galkin D. V. Ot kiberneticheskix avtomatov k iskusstvennoj zhizni: teoreticheskie i istoriko-kul' turny'e aspekty' formirovaniya cifrovoj kul'tury' (From cybernetic machines to artificial life: theoretical and historical and cultural aspects of the formation of digital culture): avtoref. dis. ... d-ra filosof. nauk. Tomsk, 2013. $51 \mathrm{p}$.

3. Zlobina S. N., Glushach N. N. Kreativno-orientirovannoe obrazovanie - novy`j obrazovatel’ny`j put’ podgotovki sovremenny' $x$ specialistov (Creative-oriented education is a new educational way of training modern specialists ) // Mezhdunar. nauch. shkola psixologii i pedagogiki VII (15). Novosibirsk, 2015. Pp. $33-36$

4. Kaveczkij I. T. Osnovy' psixologii i pedagogiki (Fundamentals of Psychology and Pedagogy)/ I. T. Kaveczkij, T. L. Ry'zhkovskaya, I. A. Koverzneva, V. G. Ignatovich, N. A. Loban, S. V. Starovojtova. Minsk.: Izd-vo MIU, 2010. 
5. Kamneva N. A. Soderzhanie obucheniya professional no-orientirovannomu inostrannomu yazy' ku (The content of teaching a professionally-oriented foreign language) // Konferenciya: Gumanitarnoe obrazovanie v e'konomicheskom vuze - 2016. URL: http://sdo.rea.ru/cde /conference/23/file.php?fileId=62lk

6. Nikolaeva N. V. Obrazovatel' ny 'e kvest-proekty' kak metod i sredstvo razvitiya navy 'kov informacionnoj deyatel' nosti uchashhixsya (Educational quest-projects as a method and means of developing information skills of students) // Voprosy` internet-obrazovaniya. 2002. № 7. URL: http://vio.fio.ru/vio_07 (data obrashheniya: 15.03.2017)

7. Polonskij V. M. Nauchno-pedagogicheskaya informaciya (Scientific and pedagogical information): slovar'spravochnik. M.: Novaya shkola, 1995. 256 p.

8. Sergeeva I. L. Transformaciya massovoj kul' tury' $v$ cifrovoj srede (Transformation of mass culture in the digital environment) // Kul tura i civilizaciya. 2016. T. 6. № 6A. Pp. 55-65.

9. Sigov A. S., Mordvinov V. A., Trifonov N. I. Modelirovanie ispol zovaniya karmanny'x komp yuterov $\mathrm{v}$ distancionnom obrazovanii (Modeling the use of handheld computers in distance education) // Informacionny'e texnologii v obrazovanii: sb. nauch. tr. M.: MIFI, 2000. Ch. III. Pp. 79-80

10. Sokolova N. L. Cifrovaya kul' tura ili kul tura v cifrovuyu e'poxu (Digital Culture or Culture in the Digital Age ) [E' lektronny'j resurs] // Mezhdunarodny'j zhurnal issledovanij kul tury'. 2012. № 3. S. 6-10. - Rezhim dostupa:http://www. Culturalresearch .ru/files/open_issues/03_2012/I JCR_03\%288\%29_2012.pdf.

\section{СВЕДЕНИЯ ОБ АВТОРАХ}

Григорян Тельман Гарикович, аспирант, Северо-Кавказский федеральный университет, Россия, г. Ставрополь. E-mail: Telman_92@mail.ru

Ломтева Татьяна Николаевна, доктор педагогических наук, профессор, заведующий кафедрой романо-германского языкознания и межкультурной коммуникации, профессор, Северо-Кавказский федеральный университет, Россия, г. Ставрополь. E-mail: rgya-mk@yandex.ru

\section{INFORMATION ABOUT AUTHORS}

Grigoryan Telman, Postgraduate, North-Caucasian Federal University, Russia, Stavropol. E-mail: Telman_92@, mail.ru

Lomteva Tatiana, Doctor of Pedagogical Sciences, Professor, Head of Linguistics and Intercultural Communication Department, North-Caucasian Federal University, Russia, Stavropol. E-mail: rgya-mk@yandex.ru 